\title{
Lymphoproliferative and cytotoxic responses of human peripheral blood mononuclear cells to mannoprotein constituents of Candida albicans
}

\author{
Antonella Torosantucci, ${ }^{1}$ Carla Palma, ${ }^{1}$ Maria Boccanera, ${ }^{1}$ Clara M. Ausiello, ${ }^{2}$ \\ Giulio C. Spagnoli ${ }^{2}$ and Antonio Cassone ${ }^{1 *}$ \\ ${ }^{1}$ Laboratory of Bacteriology and Medical Mycology, Istituto Superiore de Sanità, Viale Regina Elena 299, \\ 00161 Rome, Italy \\ ${ }^{2}$ Istituto CNR, Tipizzazione Tissutale e Problemi della Dialisi, Rome, Italy
}

(Received 22 March 1990; revised 29 June 1990; accepted 2 August 1990)

\begin{abstract}
Two major proteoglycan constituents (designated F1 and F2) of the cell wall of Candida albicans were separated by ion-exchange chromatography from a crude carbohydrate-rich extract (GMP), and investigated for their chemical and molecular composition, antigenicity and immunomodulatory properties in cultures of human peripheral blood mononuclear cells (PBMC). Both fractions consisted predominantly of Periodic acid-Schiff (PAS) and concanavalin A (Con A)-reactive material consisting of $>90 \%$ mannose, 3-5\% protein and small amounts of phosphorus; each was recognized by an anti-Candida rabbit serum as well as by a monoclonal antibody (mAb AF1) directed against an oligosaccharide epitope present on the fungal cell surface. When F1 and F2 were subjected to SDS-PAGE, transblotted and stained with enzyme-conjugated mAb AF1 or Con A, most of the antibody or lectin bound to high molecular mass ( $>200 \mathrm{kDa}$ ) polydisperse material, some of which was present in F2 (as in the starting GMP extract) but absent in F1. This difference was also observed in PAS-stained gels of the two fractions. The F2, but not the F1, constituent was as active as the unfractionated GMP extract in inducing lymphoproliferation, production of the cytokines interleukin-2 and interferon- $\gamma$, and generation of cytotoxicity against a natural-killer-sensitive target cell line (K562). These immunomodulatory properties were, like those possessed by GMP, protease-sensitive and heat-stable. Treatment of PBMC cultures with a modulatory anti-Tcell receptor antibody abolished the lymphoproliferation induced by GMP and F2 but not that induced by phytohaemagglutinin, showing that the mannoprotein materials of $C$. albicans acted through interaction with the antigen receptor complex.
\end{abstract}

\section{Introduction}

Candida albicans is a human commensal and opportunistic pathogen which possesses several distinctive properties of a potent biological response modifier (Cassone et al., 1987; Domer et al., 1988). It is important to investigate these properties in detail, as their comprehension may offer additional insight into the nature of the Candida-host relationship, both in normal subjects and in patients with candidosis. As an example of biological response modifier properties of this fungus, the activation of non-MHC-restricted antitumour cytotoxic effectors is well established (Weinberg \& Hibbs,

Abbreviations: Con A, concanavalin A; E : T, effector : target; GMP, glucomannoprotein; IFN, interferon; IL-2, interleukin-2; mAb, monoclonal antibody; MHC, major histocompatibility complex; PAS, periodic acid-Schiff; PBMC, peripheral blood mononuclear cells; PHA, phytohaemagglutinin.
1979; Cassone et al., 1981; Marconi et al., 1983, 1985; Wojdani \& Ghoneum, 1987; Djeu et al., 1988; Scaringi et $a l ., 1988,1990)$. It is also clear that at least part of these immunomodulatory effects of $C$. albicans can be induced by mannoprotein constituents from its cell wall. In addition to glucan, a mannoprotein extract was highly effective in activating natural killer cells and macrophages in mouse peritoneal cavity (Scaringi et al., 1988), or in stimulating lymphoproliferation and non-MHC restricted cytotoxicity in in vitro-cultured human peripheral blood mononuclear cells (PBMC) (Ausiello et al., 1986, 1989). Many other immunomodulatory effects, including the induction of immunosuppressive activities against both $B$ and $T$ cell-mediated responses, have been also ascribed to mannoproteins or 'mannan' of $C$. albicans (Carrow \& Domer, 1985; Cuff et al., 1986, 1989; Durandy et al., 1987; Podzorski et al., 1989, 1990). In view of the complexity of the biological response 
modifier properties expressed by candidal mannoproteins, including both immunoenhancing and immunosuppressive effects (Domer et al., 1986, 1987), it is important to examine distinct mannoprotein fractions separately for their immunological effects. This paper focuses on chromatographically separated, chemically and antigenically defined mannoprotein fractions that are responsible for the overall immunoenhancing activity of the crude mannoprotein extract of $C$. albicans.

\section{Methods}

Preparation of cell wall mannoprotein extract of $C$. albicans. The cell wall glucomannoprotein extract (GMP) was obtained from a clinical isolate of C. albicans (strain BP) as previously reported (Ausiello et al., 1986). Briefly, washed yeast cells were autoclaved in a neutral buffer $\left(140{ }^{\circ} \mathrm{C}, 2 \mathrm{~h}\right)$, and the cell lysate was precipitated in cold ethanol and extracted with chloroform/butanol $(5: 1, v / v)$. The aqueous phase was extensively dialysed against water and lyophilized.

Chromatographic fractionation of the extract. The GMP extract was subjected to ion-exchange chromatography essentially as described elsewhere (Cassone, 1989; Torosantucci et al., 1990). Briefly, $200 \mathrm{mg}$ GMP, dissolved in water, was loaded on a $241 \times 2.6 \mathrm{~cm}$ column of DEAE-Sephadex A-50 (Pharmacia) in 0.05 $\mathrm{M}-\mathrm{Tris} / \mathrm{HCl} \mathrm{pH} \mathrm{7.5.} \mathrm{After} \mathrm{a}$ prolonged wash with the equilibrating buffer to remove unbound material, retained fractions were eluted with two consecutive linear gradients of increasing $\mathrm{NaCl}$ concentration $(0.1-0.4 \mathrm{M}$ and $0.4-2.0 \mathrm{M}$, respectively). The eluate was collected in $7 \mathrm{ml}$ fractions which were assayed for polysaccharide content and absorbance at $260 \mathrm{~nm}$. Fractions corresponding to polysaccharide peaks were pooled, extensively dialysed against water and lyophilized. The final yield was about $82 \%$ of the loaded polysaccharide. Each fraction was subjected to the limulus lysate gelification test (PBI, Milan) to detect endotoxin (lipopolysaccharide) contamination.

Analytical determinations. Protein concentrations were determined by Lowry's method, using bovine serum albumin (BSA) as the standard. Total polysaccharide was determined by the phenol/sulphuric acid method according to Dubois et al. (1956), using glucose as the standard. 'Mannan' was defined as Fehling-precipitable, saccharide-positive material (see also Torosantucci et al., 1990). Because of the very low percentage of glucan in GMP (Ausiello et al., 1986; Scaringi $e t$ al., 1988), this mannan closely paralleled the amount of mannose determined by gas chromatography (Scaringi et al., 1988). Total phosphorus was assayed by the method of Chen et al. (1956).

$S D S-P A G E$ analysis. Samples containing an appropriate amount of crude mannoprotein extract or chromatographic fractions were subjected to SDS-PAGE according to Laemmli (1970), using either $10 \%$ or $5-10 \%(\mathrm{w} / \mathrm{v})$ gradient acrylamide polymers as separating gels and $4.5 \%$ or $3.5 \%$ acrylamide slabs as stacking gels. The gels were either stained with periodic acid-Schiff (PAS) reagent or transblotted onto nitrocellulose paper and stained with the monoclonal antibody (mAb) AF1 (see below) followed by phosphatase-conjugated, affinitypurified goat anti-mouse-IgM antibodies (Sigma), as previously described (Torosantucci et al., 1990). Alternatively, the blots were stained with peroxidase-conjugated concanavalin A (Con A), as follows. The nitrocellulose sheets were saturated by incubation for $1 \mathrm{~h}$ at room temperature with $3 \%(\mathrm{w} / \mathrm{v}) \mathrm{BSA}$ in $0.01 \mathrm{M}-\mathrm{Tris} / \mathrm{HCl}$ buffer, pH 7.5, containing $1 \mathrm{~mm}-\mathrm{CaCl}_{2}$ and $1 \mathrm{~mm}-\mathrm{MnCl}_{2}$ (TCM), then incubated overnight at $4{ }^{\circ} \mathrm{C}$ with peroxidase-conjugated Con $\mathrm{A}$ (Sigma) at a concentration of $0.052 \mathrm{U} \mathrm{ml}^{-1}$, in TCM. After extensive washings with TCM, the bound lectin was detected by treating the sheets with $20 \mathrm{~mm}-\mathrm{Tris} / \mathrm{HCl}$, pH 7.5, containing $\mathrm{NaCl}(500 \mathrm{~mm})$, 4-chloro-1naphthol $\left(0.5 \mathrm{mg} \mathrm{ml}^{-1}\right)$, methanol $(17 \%, \mathrm{v} / \mathrm{v})$ and hydrogen peroxide $(0.017 \%)$, as the peroxidase substrate.

Reactivity with antibodies. The crude mannoprotein extract and its chromatographic fractions were assayed for their reactivity with antiCandida serum and with $\mathrm{mAb} A F 1$, directed against an oligosaccharide epitope of the candidal cell surface (Cassone et al., 1988; Torosantucci et al., 1990). An indirect ELISA and an ELISA-inhibition assay were used, as reported previously (Ausiello et al., 1986; Scaringi et al., 1988; Cassone et al., 1988). The polyclonal serum was generated in rabbits by immunization with four subcutaneous administrations, at weekly intervals, of $2 \times 10^{7}$ glutaraldehyde-inactivated cells of $C$. albicans strain BP (Ausiello et al., 1986). The candidal cells were mixed $1: 1$ with Freund's complete adjuvant (the first two injections) or with saline (the second two injections), in a total injected volume of $1 \mathrm{ml}$. Blood was taken by cardiopuncture and the serum heated at $65^{\circ} \mathrm{C}$ for $30 \mathrm{~min}$ before reaction with appropriate antigen. $\mathrm{mAb} A F 1$ was purified by protein A-MAPS II buffer affinity chromatography, as detailed elsewhere (Mariani et al., 1989). Both the polyclonal serum and $\mathrm{mAb}$ AF1 had a titre $>1: 100000$ in an ELISA reaction using $5 \mu \mathrm{g}$ GMP $\mathrm{ml}^{-1}$ as coating antigen.

Mannoprotein treatments. Samples (10 mg) of GMP or fractions were dissolved in $5 \mathrm{ml}$ phosphate-buffered saline (PBS) containing $0.5 \mathrm{mg}$ pronase (grade A, Sigma) and the mixture was incubated overnight at $37^{\circ} \mathrm{C}$. The pronase was then precipitated by heating at $100^{\circ} \mathrm{C}$ for $10 \mathrm{~min}$; the mixture was centrifuged, the precipitate discarded and the supernatant dialysed extensively against PBS. Control samples (heattreated material) were suspended in pronase-free PBS, left overnigh at $37^{\circ} \mathrm{C}$, then heated and processed as described above. The proteolytic treatment consistently removed more than $80 \%$ of protein material from both the initial extract and the purified fraction, whereas the heat treatment alone left the chemical composition of treated materials almost unaltered.

PBMC preparation and proliferation assays. PBMC of normal healthy adult donors were isolated, cultured and stimulated with phytohaemagglutinin (PHA), anti-CD3 mAbs, GMP and mannoprotein constituents, essentially as described previously (Ausiello et al., 1986, 1989). Briefly, 96-well trays containing $10^{6} \mathrm{PBMC} \mathrm{ml}^{-1}$ and the established dose of each inducer or reagent (as indicated in single experiments) in complete RPMI medium containing $10 \%(\mathrm{v} / \mathrm{v})$ pooled human $A B$ serum were incubated for different times under $5 \%(v / v)$ $\mathrm{CO}_{2}$ at $37^{\circ} \mathrm{C}$. Each batch of human serum used did not contain antiCandida antibodies detectable by a slide agglutination test. Cell proliferation was measured as $\left[{ }^{3} \mathrm{H}\right]$ thymidine incorporation. In selected experiments, PBMC were pretreated for $24 \mathrm{~h}$ with the non-mitogenic anti-CD3 mAb CBT3-M, then washed and incubated with or without stimulants as indicated in each experiment.

Generation of cytotoxic effector cells and measurement of cytotoxicity. Freshly separated PBMC, at a concentration of $10^{6}$ cells $\mathrm{ml}^{-1}$, were incubated for $7 \mathrm{~d}$ in flat-bottomed 24-microwell trays (Nunc, Denmark) in $1 \mathrm{ml}$ volumes in the presence of putative cytotoxicity inducers. Cytotoxicity generated in these cultures was assayed against the human erythroblastoid cell line $\mathrm{K} 562$. Target cells were labelled in a $1 \mathrm{~h}$ incubation at $37^{\circ} \mathrm{C}$ with $150 \mu \mathrm{Ci}$ of a $\mathrm{Na}_{2}{ }^{51} \mathrm{CrO}_{4}$ solution [specific activity $298 \mathrm{mCi} \mathrm{ml}^{-1}\left(11 \mathrm{GBq} \mathrm{m}^{-1}\right)$, NEN-Dupont] in a final volume of $0.4 \mathrm{ml}$. After labelling and washing, cells were resuspended in complete RPMI medium and re-incubated for $30 \mathrm{~min}$ at $37^{\circ} \mathrm{C}$. Cytotoxicity assays were performed in round-bottomed 96-microwell trays, as reported elsewhere (Ausiello et al., 1989), using different effector:target $(E: T)$ ratios. The percentage of specific lysis was calculated by the formula $100 \times$ [(experimental c.p.m. minus spontane- 
ous c.p.m.)/(maximum c.p.m. minus spontaneous c.p.m.)]. Results are expressed as means of triplicate samples for each $E: T$ ratio. The standard errors of the mean, usually less than $2.0 \%$, are not shown.

Cytokine determination. Supernatants of PBMC cultures were harvested at selected intervals and assayed for interleukin-2 (IL-2) using the IL-2-dependent murine T cell line CTLL-2 (Gillis et al., 1971). The IL-2 concentration was expressed in units (U) $\mathrm{ml}^{-1}$ as described by Gillis et al. (1971), using a recombinant IL-2 preparation (kindly provided by Dr G. Garotta, Roche, Basel, Switzerland) as an internal reference standard. In the same supernatants, the titre of interferon (IFN) was determined by a previously described assay for the inhibition of Sindbis virus haemagglutinin yield after a single growth cycle (Stanton et al., 1987). IFN activity was expressed as international units (IU). It was characterized as IFN- $\gamma$ by the use of polyclonal monospecific antisera against IFN $-\alpha,-\beta$ or $-\gamma$, as previously reported (Spagnoli et al., 1985).

\section{Results}

Chromatographic separation, and chemical and antigenic characterization of mannoprotein extract

In keeping with previous reports (Cassone, 1989; Torosantucci et al., 1990), three main, well-separated components were obtained by ion-exchange chromatography of the GMP extract. One fraction (F1), representing about $15 \%$ of the material applied to the column, was not retained by the resin, being eluted before application of the $\mathrm{NaCl}$ gradient. A second fraction (F2), eluting at $0 \cdot 1-0 \cdot 2 \mathrm{M}-\mathrm{NaCl}$, was the most abundantly recovered $(47.6 \%$ of the material applied to the column). A third distinct constituent (F5), with strong absorbance at $260 \mathrm{~nm}$ and relatively high phosphorus content, was eluted at the highest salt concentration. It represented about $18 \%$ of the starting material. Minor, poorly resolved saccharide materials (F3 and $\mathrm{F} 4)$ were eluted between 0.4 and $0.6 \mathrm{M}-\mathrm{NaCl}$, but, because of their paucity, they were not analysed further or investigated for their immunomodulatory effects.

Fractions $F 1$ and $F 4$ were all strongly reactive in ELISA with the polyclonal anti-Candida serum whereas fraction F5 reacted weakly with it. Fractions F1 to F4 also contained a sugar epitope (probably an oligomanno- side) recognized by mAb AF1 (Cassone et al., 1988). Fraction F5 did not react with this $\mathrm{mAb}$. The serological specificity of the fractions was maintained after heat treatment and deproteinization (see below and Cassone et al., 1988).

Chemically (Table 1), both the resin-unbound (F1) and the low-salt-eluted (F2) fractions were composed predominantly of mannoprotein with a low but detectable phosphorus content. That mannose was the predominant sugar constituent of F1 and F2 was confirmed by gasliquid chromatography $(93.6 \%$ and $91.9 \%$ mannose in $\mathrm{F} 2$ and $\mathrm{F} 1$, respectively). Protein was more abundant in F2 than in F1 $(5.0 \%$ vs $2.6 \%)$. Fraction F5 contained relatively little polysaccharide $(22 \%)$. Its strong absorbance at $260 \mathrm{~nm}$ and high phosphorus content (relative to the other fractions) suggested that nucleic acid was a major component. In addition, fraction F5 was the only one to give a (slightly) positive limulus lysate test, indicating the presence of some contaminating endotoxin. Thus, this fraction was used as an impurity and negative control in further experiments (see below).

When fractions F1 and F2 were run in SDS-PAGE at $10 \%$ gel concentration and immunoblotted with $\mathrm{mAb}$ AF1 or stained with PAS, each showed polydisperse material of high molecular mass $(>200 \mathrm{kDa})$ which barely penetrated the separating gel (Fig. $1 a, b$ ). F2 was more disperse than $F 1$, and contained materials smearing towards lower molecular mass regions, as evident in the PAS-stained gel. Some of this material was present in GMP but absent in F1. Low molecular mass $(<30 \mathrm{kDa})$ PAS-staining material was present only in the GMP extract (Fig. $1 a$ ).

More details were observed when the fractions were run in $5-10 \%$ acrylamide gradient gels, transblotted and reacted with Con A-peroxidase conjugate (Fig. 2). Although maintaining their pronounced polydispersity, the extracts were resolved as discrete, though poorly defined, bands or regions. As in PAS-stained gels (Fig. $1 a$ ) one marked difference between fractions F1 and F2 was the absence in the former of part of the component in the high molecular mass region close to the origin of the

Table 1. Crude chemical composition of GMP and its main subfractions

Values are expressed in $\mu \mathrm{g}$ per $100 \mu \mathrm{g}$ of lyophilized material of a batch of GMP preparation (GMP-8) that was used for all experiments reported in this paper. Minor batch-to-batch variations in the chemical composition were noted in equally active preparations of GMP.

\begin{tabular}{lcrcc}
\hline \hline Material & $\begin{array}{c}\text { Total } \\
\text { polysaccharides }\end{array}$ & Mannan & Protein & Phosphorus \\
\hline Unfractionated & & & & \\
GMP & 72.5 & 68.8 & 8.4 & 2.7 \\
F1 & $>95.0$ & $>95.0$ & 2.6 & 0.01 \\
F2 & $>95.0$ & $>90.0$ & 5.0 & 0.03 \\
F5 & 22.0 & 1.5 & 2.5 & 3.3 \\
\hline \hline
\end{tabular}




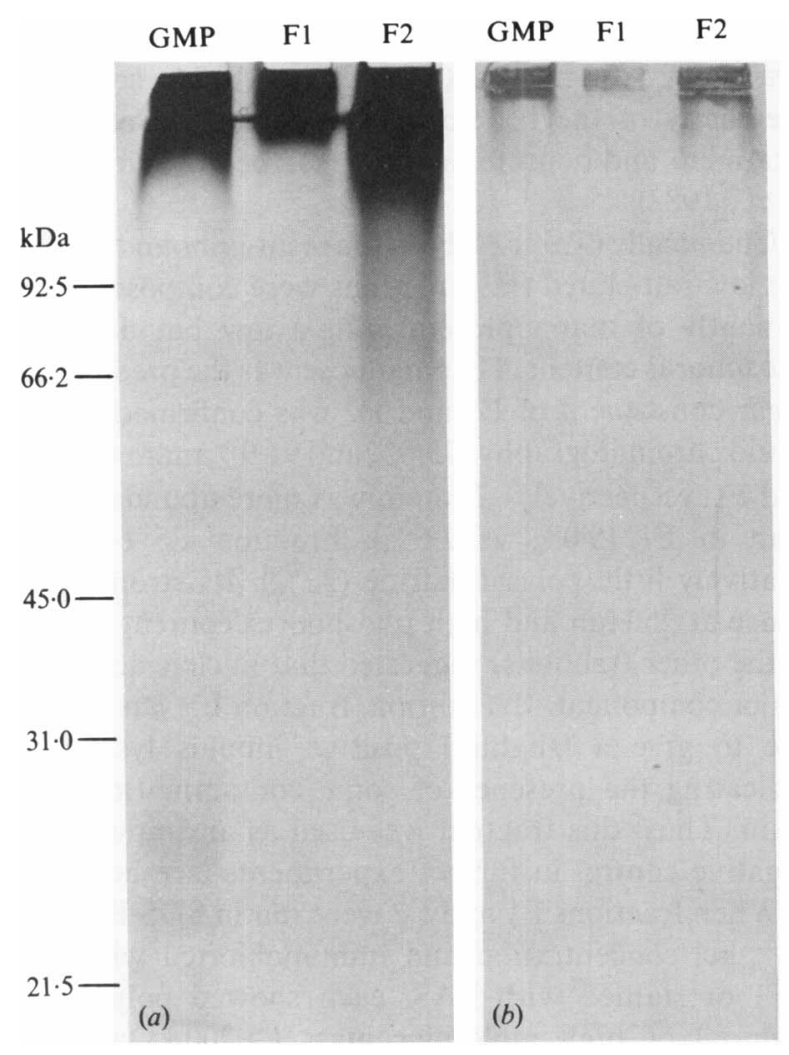

Fig. 1. SDS-PAGE ( $10 \%$ gel concentration) of GMP and chromatographic fractions F1 and F2, stained with PAS (a) or immunoblotted with mAb AF1 $(b)$. In (a), each lane contained $1 \mathrm{mg}$ of material; in $(b)$, each lane contained $20 \mu \mathrm{g}$ of material.

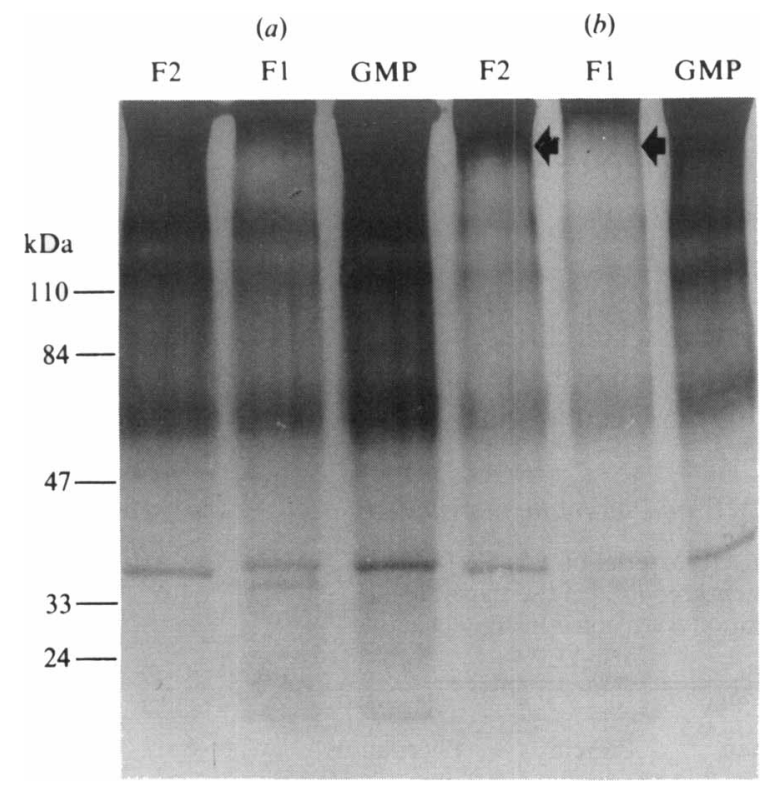

Fig. 2. SDS-PAGE (5-10\% gradient gel) of GMP and chromatographic fractions F1 and F2, run at doses of $200 \mu \mathrm{g}(a)$ or $100 \mu \mathrm{g}(b)$, transblotted and stained with peroxidase-conjugated Con $\mathrm{A}$. The experimental conditions are described in Methods. The arrows are explained in the text.

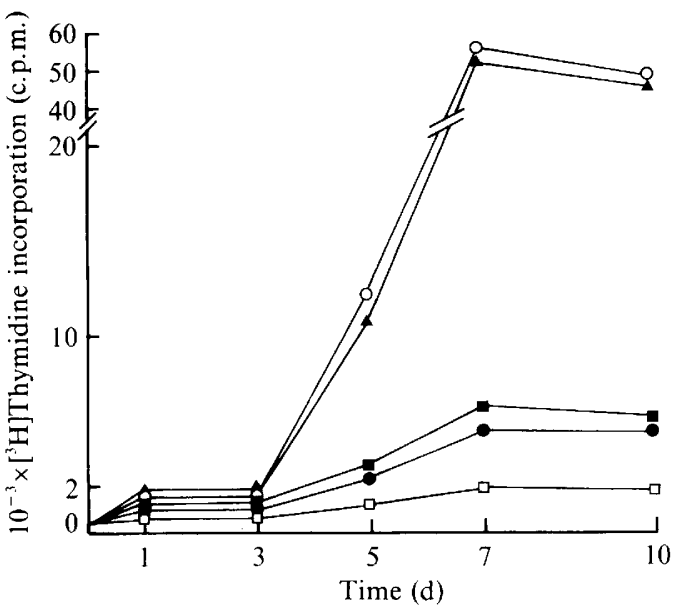

Fig. 3. Kinetics of PBMC proliferation after stimulation with GMP

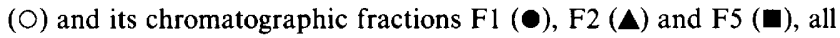
used at $50 \mu \mathrm{g} \mathrm{ml}^{-1}$ in each PBMC culture. $\square$, Untreated PBMC culture from the same donor (control).

gel (arrows in Fig. 2). This component was present in both GMP and F2. Three main bands (two with a molecular mass above $110 \mathrm{kDa}$ and one in a broad region around $65 \mathrm{kDa}$ ) were present in both fractions. A few well-defined mannoprotein bands were also present (at $35-36 \mathrm{kDa}$ ) in the two fractions (Fig. 2).

\section{Lymphoproliferation and generation of anti-K562 cytotoxicity by mannoprotein fractions}

The two predominant mannoprotein fractions ( $\mathrm{F} 1$ and F2) were compared to the crude mannoprotein extract (GMP) and to the impure fraction (F5) for their capacity to induce lymphoproliferation, production of the cytokines IL- 2 and IFN- $\gamma$, and cytotoxicity in human PBMC from normal donors. In a series of preliminary experiments, PBMC were exposed to different doses of Candida-derived material and cultured for $10 \mathrm{~d}$ to examine the kinetics of immunostimulation. Fig. 3 shows a typical experiments where PBMC were incubated for $10 \mathrm{~d}$ with $50 \mu \mathrm{g} \mathrm{ml}^{-1}$ of each material. Proliferation of GMP-stimulated PBMC was detectable on day 5 and reached a plateau on days $7-10$, confirming previous reports (Ausiello et al., 1986). Of the three fractions examined, only $F 2$ induced PBMC proliferation, similar, in extent and time-course, to that induced by the unfractionated extract; F1 and F5 showed minimal, if any, activity (Fig. 3). In the same experiment, cytotoxicity, as measured by lysis of K562 tumour target cells, was also significantly induced by candidal material on days 7-10 (data not shown). For this reason, day 7 was selected to measure lymphoproliferation and K562 lysis by Candida fractions.

Table 2 shows the results obtained with PBMC from three normal subjects (different from the one used in the 
Table 2. Proliferation and generation of cytotoxic activity in PBMC stimulated for $7 d$ with GMP and its fractions

\begin{tabular}{|c|c|c|c|c|c|c|c|}
\hline \multirow[b]{2}{*}{ Antigen } & \multirow{2}{*}{$\begin{array}{c}\text { Dose } \\
\left(\mu \mathrm{g} \mathrm{ml}^{-1}\right)\end{array}$} & \multicolumn{3}{|c|}{$\begin{array}{l}\text { Proliferation }\left(10^{-3} \times\left[{ }^{3} \mathrm{H}\right] \text { thymidine }\right. \\
\text { incorporation, c.p.m., } \pm \mathrm{SD})\end{array}$} & \multicolumn{3}{|c|}{$\begin{array}{l}\text { Cytotoxic activity* } \\
\text { (\% specific lysis) at } \mathrm{E}: \mathrm{T}\end{array}$} \\
\hline & & Donor 1 & Donor 2 & Donor 3 & $50: 1$ & $20: 1$ & $10: 1$ \\
\hline $\begin{array}{l}\text { None } \\
\text { Unfractionated } \\
\text { GMP }\end{array}$ & $\begin{array}{l}- \\
50 \\
5 \\
0.5\end{array}$ & $\begin{array}{c}0.91 \pm 0.09 \\
6.3 \pm 1.0 \\
7.8 \pm 3.4 \\
12.8 \pm 2.9\end{array}$ & $\begin{array}{l}0.58 \pm 0.05 \\
10 \cdot 7 \pm 1.6 \\
16.5 \pm 0 \cdot 8 \\
13.5 \pm 3 \cdot 1\end{array}$ & $\begin{array}{r}2 \cdot 5 \pm 0 \cdot 8 \\
55 \cdot 7 \pm 6 \cdot 7 \\
38 \cdot 3 \pm 7 \cdot 7 \\
-\end{array}$ & $\begin{array}{l}24 \cdot 0 \\
95 \cdot 7 \dagger \\
95 \cdot 5 \dagger \\
--\end{array}$ & $\begin{array}{c}19 \cdot 6 \\
94 \cdot 7 \dagger \\
78 \cdot 1 \dagger \\
-\end{array}$ & $\begin{array}{c}7 \cdot 9 \\
79 \cdot 4 \dagger \\
65 \cdot 8 \dagger \\
-\end{array}$ \\
\hline F1 & $\begin{array}{l}50 \\
5 \\
0 \cdot 5\end{array}$ & $\begin{array}{l}1.9 \pm 0.3 \\
1.2 \pm 0.1 \\
0.8 \pm 0.2\end{array}$ & $\begin{array}{l}1.8 \pm 0.3 \\
1.7 \pm 0.2 \\
0.9 \pm 0.5\end{array}$ & $\begin{array}{c}4 \cdot 8 \pm 0 \cdot 9 \\
5 \cdot 2 \pm 2 \cdot 6 \\
-\end{array}$ & $\begin{array}{c}79 \cdot 0 \dagger \\
64 \cdot 0 \dagger \\
-\end{array}$ & $\begin{array}{c}55 \cdot 0+ \\
39 \cdot 0 \\
-\end{array}$ & $\begin{array}{c}37 \cdot 5 \ddagger \\
28 \cdot 2 \\
-\end{array}$ \\
\hline F2 & $\begin{array}{l}50 \\
5 \\
0.5\end{array}$ & $\begin{array}{l}6.9 \pm 3.7 \\
3.3 \pm 0.8 \\
1 \cdot 6 \pm 0.7\end{array}$ & $\begin{array}{r}14.4 \pm 3.9 \\
7.7 \pm 2.0 \\
1.6 \pm 0.3\end{array}$ & $\begin{array}{l}52 \cdot 1 \pm 8 \cdot 6 \\
21 \cdot 7 \pm 4 \cdot 7 \\
15 \cdot 3 \pm 2 \cdot 1\end{array}$ & $\begin{array}{c}98 \cdot 2 \dagger \\
83 \cdot 2 \dagger \\
-\end{array}$ & $\begin{array}{c}85.8+ \\
81.9+ \\
-\end{array}$ & $\begin{array}{c}76 \cdot 4 \dagger \\
66 \cdot 5 \dagger \\
-\end{array}$ \\
\hline F5 & $\begin{array}{l}50 \\
5 \\
0.5\end{array}$ & $\begin{array}{l}1.2 \pm 0.4 \\
0.9 \pm 0.2 \\
0.2 \pm 0.02\end{array}$ & $\begin{array}{l}2.4 \pm 0.6 \\
0.8 \pm 0.2 \\
0.7 \pm 0.3\end{array}$ & $\begin{array}{c}5 \cdot 2 \pm 2 \cdot 0 \\
2 \cdot 4 \pm 0 \cdot 7 \\
-\end{array}$ & $\begin{array}{c}39 \cdot 9 \\
- \\
-\end{array}$ & $\begin{array}{c}36 \cdot 0 \\
- \\
-\end{array}$ & $\begin{array}{c}8 \cdot 6 \\
- \\
-\end{array}$ \\
\hline
\end{tabular}

* Measured as lysis of $\mathrm{K} 562$ cells in $4 \mathrm{~h}{ }^{51} \mathrm{Cr}$-release assay using the cells from donor 3 as lytic effectors.

$\dagger P<0.01$ (Student's $t$ test), as compared to the control, unstimulated culture.

$\ddagger P<0.05$, as above.

experiment shown in Fig. 3) stimulated with GMP and its fractions at doses of $0.5,5$ and $50 \mu \mathrm{g} \mathrm{ml}^{-1}$. F2 was the only chromatographic fraction to induce significant, dose-dependent, lymphoproliferation. Both F1 and F5 were inactive, even at $50 \mu \mathrm{g} \mathrm{ml}^{-1}$. The generation of anti-K562 cytotoxicity was manifested in F2-treated PBMC, but some lytic activity was also generated in F1treated cultures, especially when assayed at the highest $\mathrm{E}: \mathrm{T}$ ratio (Table 2). Fraction $\mathrm{F} 5$ did not stimulate lymphoproliferation or cytotoxicity.

\section{Cytokine production}

The production of the cytokines IL-2 and IFN- $\gamma$, which are particularly important in the proliferation and cytotoxicity of PBMC (Balkwill \& Burke, 1989), was also investigated in PBMC stimulated by candidal fractions. In one typical experiment (out of four performed), shown in Table 3, significant IL-2 and IFN production were detected with the same materials (GMP and F2) which stimulated lymphoproliferation. With cells from the donor reported in Table 3, an amount of IFN- $\gamma$ (300 IU per $\mathrm{ml}$ of culture) equalling that given by incubation of PBMC with $100 \mathrm{U}$ of recombinant IL-2 $\mathrm{ml}^{-1}$ was measured. In keeping with its inability to stimulate lymphoproliferation, fraction $\mathrm{F} 1$ did not induce the production of appreciable quantities of IL-2. However, this fraction was able to induce some IFN production (Table 3, Fig. 4). The kinetics of IL-2 and IFN production after stimulation with Candida-derived materials is shown in Fig. $4(a, b)$, which refers to a typical experiment performed with PBMC of a donor different from that used in the experiment reported in Table 3.
Both GMP and F2 induced cytokine production, which was maximal on day 2 for IL-2 and on day 7 for IFN (Fig. 4 and data not shown). For this particular PBMC donor, $500 \mathrm{IU}$ of IFN were produced by F2-stimulated PBMC. Although there were quantitative differences between donors in the degree of GMP- and F2-stimulation of cytokine production, the qualitative pattern was comparable and reproducible in all seven donors examined. The IFN was characterized as IFN- $\gamma$ by the use of sera specific for IFN- $\alpha,-\beta$ or $-\gamma$ (Spagnoli et al., 1985).

\section{The antigenic nature of lymphoproliferation induced by} mannoprotein fractions

We previously demonstrated that GMP-induced lymphoproliferation was antigenic in nature (Ausiello et al., 1986). To extend this finding to the $F 2$ mannoprotein fraction, we used an anti-CD3 mAb (CBT3-M) which is unable to induce lymphoproliferation but, through binding to the CD3Ti complex, induces TCR modulation, thus inhibiting antigen-specific proliferation (Alcover et al., 1987). The results of an experiment with two donors are summarized in Table 4 , which shows that proliferation induced by either GMP or its $F 2$ fraction was virtually abolished in CBT3-M-treated PBMC, while PHA-stimulated lymphoproliferation was unaffected.

Effect of protease or heat treatment on the immunological activity of GMP and fraction $F 2$

As both GMP and its active immunomodulatory constituent $\mathrm{F} 2$ had protein moieties, it was of interest to 
Table 3. Proliferation and cytokine production in cultures of human PBMC, unstimulated or stimulated with candidal materials and human recombinant interleukin-2 (rIL-2)

PBMC were cultured without or with the indicated stimulant, at the desired concentration, at $37^{\circ} \mathrm{C}$. Proliferation, measured by $\left[{ }^{3} \mathrm{H}\right]$ thymidine incorporation, was assessed on day 7 of the culture; IL- 2 and IFN- $\gamma$ production were assayed on days 2 and 7 , respectively (see also Fig. 4).

\begin{tabular}{|c|c|c|c|c|}
\hline Stimulant & $\begin{array}{c}\text { Dose } \\
\left(\mu \mathrm{g} \mathrm{ml}^{-1}\right)\end{array}$ & $\begin{array}{l}\text { PBMC proliferation } \\
\left(10^{-3} \times \text { c.p.m., } \pm \text { SD }\right)\end{array}$ & $\begin{array}{c}\mathrm{IL}-2 \\
\left(\mathrm{U} \mathrm{ml}^{-1}\right)\end{array}$ & $\begin{array}{c}\text { IFN- } \gamma \\
\left(\mathrm{IU} \mathrm{ml} \mathrm{m}^{-1}\right)\end{array}$ \\
\hline None & - & $4 \cdot 5 \pm 1 \cdot 3$ & 0.8 & 10 \\
\hline GMP & $\begin{array}{r}50 \\
5\end{array}$ & $\begin{array}{l}43.8 \pm 1.9 \\
30.0 \pm 2.3\end{array}$ & $\begin{array}{l}5 \cdot 9^{*} \\
2 \cdot 1\end{array}$ & $\begin{array}{l}100^{*} \\
30\end{array}$ \\
\hline F1 & $\begin{array}{r}50 \\
5\end{array}$ & $\begin{array}{l}5 \cdot 5 \pm 1 \cdot 4 \\
4 \cdot 0 \pm 2 \cdot 5\end{array}$ & $\begin{array}{l}1.0 \\
0.8\end{array}$ & $\begin{array}{l}100^{*} \\
20\end{array}$ \\
\hline F2 & $\begin{array}{r}50 \\
5\end{array}$ & $\begin{array}{l}81 \cdot 5 \pm 12 \cdot 9 \\
21 \cdot 2 \pm 8 \cdot 7\end{array}$ & $\begin{array}{l}5 \cdot 2^{*} \\
1 \cdot 7\end{array}$ & $\begin{array}{c}300^{*} \\
10\end{array}$ \\
\hline F5 & $\begin{array}{r}50 \\
5\end{array}$ & $\begin{array}{l}5.6 \pm 1.8 \\
2.9 \pm 0.7\end{array}$ & $\begin{array}{l}1.4 \\
0.9\end{array}$ & $\begin{array}{l}20 \\
10\end{array}$ \\
\hline rIL-2 & $100 \dagger$ & $41 \cdot 3 \pm 1 \cdot 0$ & - & $300^{*}$ \\
\hline
\end{tabular}

* Denotes a statistically significant $(P<0.01)$ difference with respect to the unstimulated control, as assessed by the Student's $t$ test.

$\dagger$ Units $\mathrm{ml}^{-1}$
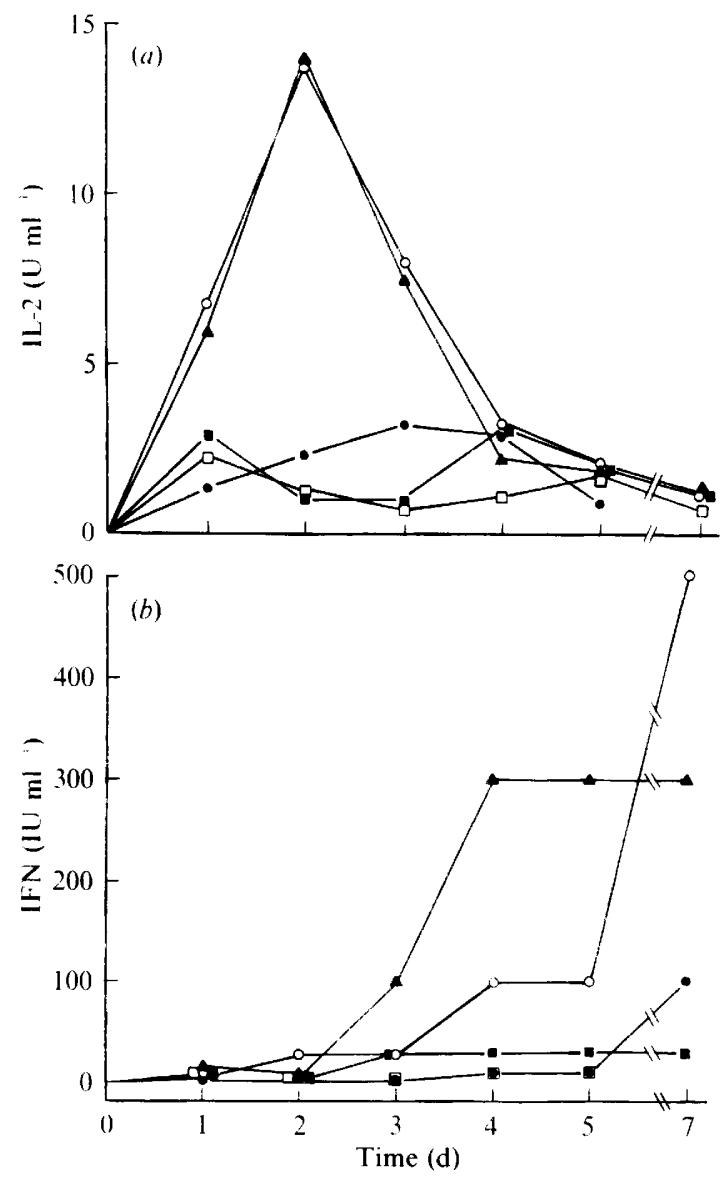

Fig. 4. Kinetics of production of IL-2 $(a)$ and IFN $(b)$ in PBMC cultures from a healthy donor unstimulated $(\square)$, or stimulated with GMP (O) or its fractions F2 (A), F1 (•) or F5 (®). Each stimulant was used at a concentration of $50 \mu \mathrm{g}$ per $\mathrm{ml}$ of PBMC culture. examine whether hydrolysis or protein modification would result in a loss of immunological activity. Materials were therefore treated with pronase, and, as the experimental procedure for pronase treatment included a non-specific precipitation in boiling water, controls containing only GMP and buffer were similarly treated at $100{ }^{\circ} \mathrm{C}$. The data from these experiments are shown in Table 5 (two donors for lymphoproliferation and one for cytotoxicity generation). Protein degradation largely, if not completely, abolished both lymphoproliferation and cytotoxicity induction by both the unfractionated extract and fraction $F 2$. Only at the highest $E: T$ ratio $(50: 1)$ was some residual cytotoxicity generated by heat- and pronase-treated Candida-derived material. Simple heat treatment of GMP and F2 did not abolish their capacity to stimulate lymphoproliferation and cytotoxicity generation (Table 5). Moreover, a control experiment performed with a pronase solution, heated as above, and incubated with PBMC, did not affect either the lymphoproliferation or cytotoxicity induction (data not shown).

\section{Discussion}

To understand better the nature of the host-Candida relationship, we have studied the antigenic and immunomodulatory activities of a mannoprotein extract, GMP, of C. albicans (Spagnoli et al., 1985; Ausiello et al., 1986, 1989; Scaringi et al., 1988). It is well known that crude 'mannan' or mannoprotein of fungal cell wall contains a 
Table 4. Effect of $m A b C B T 3-M$ on $P B M C$ proliferation induced by $G M P$, fraction $F 2$, or $P H A$

PBMC, untreated or pretreated $(24 \mathrm{~h})$ with MAb CBT3-M $\left(10 \mu \mathrm{g} \mathrm{ml}^{-1}\right)$, were stimulated with the indicated candidal material (each at $50 \mu \mathrm{g} \mathrm{ml}^{-1}$ ) or PHA [1:100 dilution of a commercial preparation (HA-15; Wellcome): see Ausiello et al. (1986)]. Proliferation was measured on day 7 or 3 for Candida- or PHA-stimulated cultures, respectively.

\begin{tabular}{|c|c|c|c|c|c|c|}
\hline \multirow[b]{3}{*}{ Stimulant } & \multicolumn{6}{|c|}{ PBMC proliferation $\left(10^{-3} \times\left[{ }^{3} \mathrm{H}\right]\right.$ thymidine incorporation, c.p.m., \pm SD $)$} \\
\hline & \multicolumn{3}{|c|}{ Donor 1} & \multicolumn{3}{|c|}{ Donor 2} \\
\hline & Untreated & CBT3-M-treated & $P^{*}$ & Untreated & CBT3-M-treated & $P^{*}$ \\
\hline None & $0 \cdot 3 \pm 0.07$ & $1 \cdot 2 \pm 0.09$ & - & $1.05 \pm 0.2$ & $0 \cdot 8 \pm 0.08$ & - \\
\hline GMP & $11 \cdot 8 \pm 2 \cdot 7$ & $1.5 \pm 0.6$ & $<0.01$ & $8 \cdot 61 \pm 1 \cdot 2$ & $0.5 \pm 0.2$ & $<0 \cdot 01$ \\
\hline Fl & $2 \cdot 6 \pm 0 \cdot 3$ & $1.9 \pm 0.4$ & NS & - & - & - \\
\hline F2 & $25.1 \pm 1.0$ & $2 \cdot 6 \pm 0.2$ & $<0.01$ & $9 \cdot 4 \pm 2 \cdot 5$ & $1 \cdot 0+0 \cdot 2$ & $<0.01$ \\
\hline F5 & $2 \cdot 1 \pm 2 \cdot 8$ & $1 \cdot 3 \pm 0 \cdot 2$ & NS & - & - & - \\
\hline PHA & $75 \cdot 4 \pm 5 \cdot 6$ & $81 \cdot 7 \pm 6 \cdot 3$ & NS & $108 \cdot 4 \pm 9 \cdot 3$ & $92 \cdot 3 \pm 9 \cdot 1$ & NS \\
\hline
\end{tabular}

* $P$ values comparing CBT3-M-treated with antibody-untreated cultures. NS, Not significant.

Table 5. Lymphoproliferation and cytotoxicity induction by immunologically active fractions after proteolytic treatment

\begin{tabular}{|c|c|c|c|c|c|c|c|c|}
\hline \multirow[b]{2}{*}{ Antigen } & \multirow{2}{*}{$\begin{array}{c}\text { Dose } \\
\left(\mu \mathrm{g} \mathrm{ml}^{-1}\right)\end{array}$} & \multicolumn{4}{|c|}{$\begin{array}{c}\text { PBMC proliferation } \\
\left(10^{-3} \times\left[{ }^{3} \mathrm{H}\right] \text { thymidine incorporation, c.p.m., } \pm \mathrm{SD}\right)\end{array}$} & \multicolumn{3}{|c|}{$\begin{array}{l}\text { Cytotoxic activity } \\
(\% \text { specific lysis) at } \mathrm{E}: \mathrm{T})\end{array}$} \\
\hline & & Donor 1 & $P^{*}$ & Donor 2 & $P^{*}$ & $50: 1$ & $20: 1$ & $10: 1$ \\
\hline None & - & $0.9 \pm 0.09$ & & $2.5 \pm 0.8$ & & $35 \cdot 0$ & $29 \cdot 7$ & $26 \cdot 1$ \\
\hline Unfractionated & 50 & $7 \cdot 0 \pm 2 \cdot 4$ & - & $55 \cdot 7 \pm 6 \cdot 7$ & - & $98 \cdot 7$ & $94 \cdot 7$ & $79 \cdot 4$ \\
\hline GMP & 5 & $9 \cdot 4 \pm 2 \cdot 1$ & - & $33 \cdot 3 \pm 7 \cdot 7$ & - & $95 \cdot 5$ & $88 \cdot 1$ & $85 \cdot 8$ \\
\hline \multirow{2}{*}{$\begin{array}{l}\text { Pronase- and heat- } \\
\text { treated GMP }\end{array}$} & 50 & $1 \cdot 3 \pm 0.3$ & $<0.01$ & $6 \cdot 1 \pm 3.6$ & $<0.01$ & $67 \cdot 5 \ddagger$ & $44 \cdot 0 \dagger$ & $31 \cdot 7 \dagger$ \\
\hline & 5 & $1 \cdot 5 \pm 0.3$ & $<0.01$ & $3 \cdot 2 \pm 1 \cdot 5$ & $<0.01$ & $55.0 \ddagger$ & $27 \cdot 6 \dagger$ & $13.7 \dagger$ \\
\hline \multirow[t]{2}{*}{ Heat-treated GMP } & 50 & $6 \cdot 2 \pm 2.0$ & NS & $50 \cdot 1 \pm 5 \cdot 5$ & NS & - & - & - \\
\hline & 5 & $8 \cdot 8 \pm 2 \cdot 2$ & NS & $28 \cdot 7 \pm 6 \cdot 3$ & NS & - & - & - \\
\hline \multirow[t]{2}{*}{$\mathrm{F} 2$} & 50 & $6.9 \pm 3.7$ & - & $52 \cdot 1 \pm 8 \cdot 6$ & - & 100 & $85 \cdot 8$ & $76 \cdot 4$ \\
\hline & 5 & $3 \cdot 3 \pm 0 \cdot 8$ & - & $21.7 \pm 4.7$ & - & $83 \cdot 2$ & $81 \cdot 9$ & 76.9 \\
\hline \multirow{2}{*}{$\begin{array}{l}\text { Pronase- and heat- } \\
\text { treated F2 }\end{array}$} & 50 & $1 \cdot 3 \pm 0 \cdot 3$ & $<0.01$ & $5 \cdot 6 \pm 2 \cdot 7$ & $<0.01$ & $56.0 \ddagger$ & $37 \cdot 0 \dagger$ & $22 \cdot 3 \dagger$ \\
\hline & 5 & $1.5 \pm 0.3$ & $<0.01$ & $6 \cdot 2 \pm 2 \cdot 8$ & $<0.01$ & $50 \cdot 4 \ddagger$ & $37.0 \dagger$ & $31 \cdot 3 \dagger$ \\
\hline Heat-treated F2 & 50 & $6 \cdot 4 \pm 1 \cdot 2$ & NS & $49 \cdot 5 \pm 2.9$ & NS & - & - & - \\
\hline
\end{tabular}

* $P$ values comparing treated versus the respective untreated antigen preparation. Ns, Not significant.

$\dagger P<0.01$ vs PBMC cultures induced by untreated GMP or F2, respectively (Student's $t$ test).

$\ddagger P<0.05$ vs PBMC cultures induced by untreated GMP or F2, respectively (Student's $t$ test).

heterogeneous mixture of constituents with relatively small differences in gross chemistry but markedly different immunological properties. Domer et al. (1988) and Cassone (1989) have recently reviewed the evidence for the varied effects of mannoprotein constituents of $C$. albicans on the immune system. Remarkably, both immunoenhancing and immunosuppressive effects have been ascribed to this material (Carrow \& Domer, 1985; Domer et al., 1986, 1987; Scaringi et al., 1988; Ausiello et al., 1989; Cuff et al., 1989), although it is not clear whether these apparently opposite effects are caused by different constituents or even by a single constituent, used in different ways or concentrations, or both. For all these reasons, the separation and identification of active mannoprotein constituents is important. Our chromatographic procedure, similar to that previously used by Domer et al. (1986) on a different mannan preparation, separated GMP into three well-resolved main peaks ( $F 1$, F2, F5), with evidence of poorly resolved minor constituents. One of the main fractions (F5) appeared to consist of a heterogeneous material, heavily contaminated by nucleoprotein. The other two fractions, F1 and F2, were essentially mannoproteins, similar in chemical composition to those obtained by others (Domer et al., 1986; Shibata et al., 1985, 1986). These latter authors used a bulk phosphomannoprotein preparation obtained by digestion of whole cells with a 1,3- $\beta$-glucanase and precipitation with Cetavlon, a procedure likely to give mostly undegraded material. With respect to this preparation, our $F 1$ and $F 2$ fractions had a higher percentage of protein and a lower phosphorus content. Other authors (Podzorski et al., 1989, 1990) have recently prepared a 'mannan' extract by fractional precipitation with Cetavlon of autoclaved Candida cells. Since the 
material contained about $10 \%$ protein, this 'mannan' is indeed a mannoprotein extract comparable to our GMP extract or fraction F2 in gross chemistry and immunological activity (Podzorski et al., 1990).

Despite the similarities in chemical composition, there must be important, immunologically relevant, molecular differences between the two mannoprotein fractions separated here, as only $F 2$ had the whole spectrum of immunological activities shown by the crude extract. Some immunomodulatory activities, in particular cytotoxicity and IFN production, were also manifested in PBMC cultures of some donors treated with the highest dose of $\mathrm{F} 1$ fraction, and it is possible either that fractions $\mathrm{F} 1$ and $\mathrm{F} 2$ partly share the inductive constituent or that different constituents may bring about the same phenomena, although with quite different efficiency.

When examined by SDS-PAGE, fractions F1 and F2 both showed polydisperse mannoprotein material with electrophoretically distinct complexes of different molecular mass. Some differences between the molecular profiles of the two fractions were noticed, in particular concerning a high molecular mass, poorly separated constituent which was absent in $\mathrm{F} 1$ but present in both F2 and GMP. It is not known whether this or some other undetected difference is relevant to the lack or the substantial reduction of PBMC-proliferation and IL-2production-inducing abilities of the $\mathrm{F} 1$ fraction. Immunologically active, mannan preparations used by others have not been examined by SDS-PAGE, so a comparison with our data is not possible. It is known, however, that mannan obtained by Fehling precipitation suffers from alkaline degradation and loss of protein (Nakajima \& Ballou, 1974; Shibata et al., 1986), and we have shown here that the protein moiety is essential for mannoprotein to be active as an immunostimulator. Interestingly, protein was also essential in the DTH-phenomenon elicited by Candida glycoprotein in experimental animals (Carrow \& Domer, 1985).

We previously presented data suggesting that Candida mannoproteins did not act as mitogens but rather as specific antigens (Ausiello et al., 1986). The experiments using anti-CD3 antibodies, showing almost total inhibition of lymphoproliferation induced by GMP or F2, but not of that induced by PHA, reinforce previous evidence. The F2 fraction was not contaminated by limulus-lysatedetectable lipopolysaccharide, while the F5 fraction, which was slightly positive, was substantially inactive in our model. This seems to rule out the possibility that some of the observed effects, in particular those conserning the cytotoxicity induction, could be due to endotoxin. The antigenic nature of Candida-derived mannoprotein-stimulated lymphoproliferation of human PBMC is also confirmed by recent data of Podzorski $e t$ al. (1990).
We are greatly indebted to Dr J. Y. Djeu, University of South Florida at Tampa, for critically reading the manuscript and helpful suggestions. We thank Mrs A. M. Marella and Mrs F. Baschieri for help in manuscript preparation. Thanks are also due to Professor F. Malavasi, University of Turin, Italy, for a generous supply of anti-CD3Ti monoclonal antibodies. The work described in this paper was supported in part by grants from the National Research Council (Italy), within the special Project 'Causes of Disease' (FATMA), and 'Progetto Nazionale AIDS' Research Units A. Cassone.

\section{References}

Alcover, A., Ramarli, D., Richardson, N. E., Chang, H. S. \& REINHERZ, E. L. (1987). Functional and molecular aspects of human $\mathrm{T}$ lymphocyte activation via T3-Ti and T11 pathways. Immunological Reviews 95, 5-35.

ausiello, C. M., Spagnoli, G. C., Boccanera, M., Casalinuovo, I., Malavasi, F., Casciani, C. U. \& Cassone, A. (1986). Proliferation of human peripheral blood mononuclear cells induced by Candida albicans and its cell wall fractions. Journal of Medical Microbiology 22, 195-202.

Ausiello, C. M., Palma, C., Spagnoli, G. C., Piazza, A., Casciani, C. U. \& CASSONE, A. (1989). Cytotoxic effectors in human peripheral blood mononuclear cells induced by a mannoprotein complex of Candida albicans: a comparison with interleukin-2-activated killer cells. Cellular Immunology 121, 349-356.

BARKWILl, F. R. \& BURKE, F. (1989). The cytokine network. Immunology Today 10, 299-304.

CARROW, E. W. \& DOMER, J. E. (1985). Immunoregulation in experimental murine candidiasis: specific suppression induced by Candida albicans cell wall glycoprotein. Infection and Immunity 49, 172-181.

CAssone, A. (1989). Cell wall of Candida albicans, its functions and its impact on the host. Current Topics Medical Mycology 3, 249-314.

Cassone, A., Marconi, P., Bistoni, F., Mattia, E., Sbaraglia, G., GaraCI, E. \& Bonmassar, E. (1981). Immunoadjuvant effect of Candida albicans and its cell wall fractions in a mouse lymphoma model. Cancer Immunology Immunotherapy 10, 181-189.

Cassone, A., Marconi, P. \& Bistoni, F. (1987). Cell wall of Candida albicans and host response. CRC Critical Reviews in Microbiology 15, 87-95.

Cassone, A., Torosantucci, A., Boccanera, M., Pellegrini, G., Palma, C. \& Malavasi, F. (1988). Production and characterization of a monoclonal antibody to a cell surface, glucomannoprotein constituent of Candida albicans and other pathogenic Candida species. Journal of Medical Microbiology 27, 233-238.

Chen, P. S., Toribara, T. Y. \& W ARNER, H. (1956). Microdetermination of phosphorus. Analytical Chemistry 28, 1756-1758.

Cuff, C. F., Rogers, C. M., LAMB, B. J. \& Rogers, T. J. (1986). Induction of suppressor cells in vitro by Candida albicans. Cellular Immunology 100, 47-56.

Cuff, C. F., Packer, B. J. \& Rogers, T. J. (1989). A further characterization of Candida albicans-induced suppressor B-cell activity. Immunology 68, 80-86.

DJeU, J. Y., Blanchard, D. K., Richards, A. L. \& Friedman, H. (1988). Tumor necrosis factor induction by Candida albicans from human natural killer cells and monocytes. Journal of Immunology 141, 4047-4052.

Domer, J. E., Stashak, P. W., Elyins, K., Prescott, B., Caldes, G. \& BAKER, P. J. (1986). Separation of immunomodulatory effects of mannan from Candida albicans into stimulatory and suppressive components. Cellular Immunology 101, 403-414.

Domer, J. E., Elkins, K. L., EnNist, D. L., Stashak, P. W., Garner, R. E. \& BAKER, P. J. (1987). Enhancement of non-Candida antibody responses by Candida albicans cell wall glycoprotein. Infection and Immunity 55, 2619-2624. 
DOMER, J., ElKINS, K., ENNIST, D. \& BAKER, P. (1988). Modulation of immune responses by surface polysaccharides of Candida albicans. Reviews of Infectious Diseases 10, 419-422.

Dubois, M., Gilles, K. A., Hamilton, J. K., Rebers, P. A. \& Smith, F. (1956). Colorimetric method for determination of sugars and related substances. Analytical Chemistry 28, 350-356.

Durandy, A., Fisher, A., Le Deist, F., Drouhet, E. \& Griscelli, C. (1987). Mannan-specific and mannan-induced T-cell suppressive activity in patients with chronic mucocutaneous candidosis. Journal of Clinical Immunology 7, 400-409.

Gillis, S., FERM, M. M., OU, W. \& SMITH, K. A. (1971). T cell growth factor: parameters of production and a quantitative microassay for activity. Journal of Immunology 120, 2077-2085.

LAEMMLI, U. K. (1970). Cleavage of structural proteins during the assembly of the head of bacteriophage T4. Nature, London 227, 680685.

Marconi, P., Cassone, A., Baccarini, M., Tissi, L., Garaci, E., Bonmassar, E., Frati, L. \& Bistoni, F. (1983). Relationship between tumor load, route of tumor inoculation and response to immunotherapy in murine lymphoma model. Journal of the National Cancer Institute 71, 299-305.

Marconi, P., Scaringi, L., Tissi, L., Boccanera, M., Bistoni, F., BONMASSAR, E. \& CASSONE, A. (1985). Induction of natural killer cell activity by inactivated Candida albicans in mice. Infection and Immunity 50, 127-134.

Mariani, M., Cianfriglia, M. \& Cassone, A. (1989). Is mouse IgM purification on protein A possible? Immunology Today 10, 115-116.

Nakajima, T. \& Ballou, C. E. (1974). Characterization of the carbohydrate fragments obtained from Saccharomyces cerevisiae mannan by alkaline degradation. Journal of Biological Chemistry 249, 7679-7684.

Podzorski, R. P., Herron, M. J., Fast, D. J. \& Nelson, R. D. (1989). Pathogenesis of candidiasis: immunosuppression by cell wall mannan catabolites. Archives of Surgery 124, 1290-1294.

Podzorski, R. P., Gray, G. R. \& Nelson, R. D. (1990). Different effects of native Candida albicans mannan and mannan-derived oligosaccharides on antigen-stimulated lymphoproliferation in vitro. Journal of Immunology 144, 707-716.
SCaringi, L., Marconi, P., Boccanera, M., Tissi, L., Bistoni, F. \& CASSONE, A. (1988). Cell wall components of Candida albicans as immunomodulators: induction of natural killer and macrophagemediated peritoneal cell cytotoxicity in mice by mannoprotein and glucan fractions. Journal of General Microbiology 134, 1265-1274.

Scaringi, L., Cornacchione, P., Rosati, E., Boccanera, M., Cassone, A., Bistoni, F. \& MarConi, P. (1990). Induction of LAK like cells in the peritoneal cavity of mice by inactivated Candida albicans. Cellular Immunology 129, 271-287.

Shibata, N., Ichikawa, T., Tojo, M. \& SuZuKI, S. (1985). Immunochemical study on the mannans of Candida albicans NIH A-207, NIH B-792, and J-1012 strains prepared by fractional precipitation with cetyltrimethylammonium bromide. Archives of Biochemistry and Biophysics 243, 338-348.

Shibata, N., Kobayashi, H., Tojo, M. \& SuzuKi, S. (1986) Characterization of phosphomannan-protein complexes isolated from viable cells of yeast and mycelial forms of Candida albicans NIH-B-792 strain by the action of Zymolyase-100T. Archives of Biochemistry and Biophysics 251, 697-708.

Spagnoli, G. C., Ausiello, C. M., Casalinuovo, I., Antonelli, G., Dianzani, F. \& Cassone, A. (1985). Candida albicans and a phosphorylated glucomannan protein fraction of its cell wall induce production of immune interferon by human peripheral blood mononuclear cells. IRCS Medical Science 13, 1190-1191.

Stanton, G. J., Langford, M. J. \& Dianzani, F. (1987). Virus yield reduction assay for IFN by titration of Sindbis virus haemagglutinin. Methods in Enzymology 78, 351-357.

Torosantucci, A., Boccanera, M., Casalinuovo, I., Pellegrini, G. \& CASSONE, A. (1990). Differences in the antigenic expression of immunomodulatory mannoprotein constituents of yeast and mycelial forms of Candida albicans. Journal of General Microbiology 136 , $1421-1428$

WeinberG, J. B. \& HiBBs, J. B. (1979). Enhanced macrophage tumoricidal activity and tumor suppression or regression caused by heat-killed Candida albicans. Journal of the National Cancer Institute 63, 1273-1278.

WOJDANI, A. \& GHONEUM, M. (1987). In vivo augmentation of natural killer cell activity by Candida albicans. International Journal of Immunopharmacology 9, 827-832. 